\title{
IUFOST2006/384
}

\section{European Food Information Resource Network of Excellence (Eu- roFIR) - Providing the Tools for Improved Nutrition and Health in Europe}

\author{
P. Finglas ${ }^{\mathrm{a}}$ and A. Moeller ${ }^{\mathrm{b}}$ \\ anstitute of Food Research, Norwich Research Park, Colney Lane, NR4 7UA Norwich, United Kingdom \\ ${ }^{\mathrm{b}}$ Danish Institute for Food and Veterinary Research, Department of Nutrition, Food Informatics, Morkhoj \\ Bygade 19, 2860 Soborg, Copenhagen, Denmark \\ paul.finglas@bbsrc.ac.uk
}

EuroFIR forms a world-leading collaboration on the development and application of a unified, reliable and accessible European Food Information Resource and comprise 110 researchers and 50 postgraduate students from 21 European countries. The principal objective is to build and disseminate a comprehensive, coherent and validated databank providing a single, authoritative source of food composition data in Europe for nutrients, and newly emerging bioactive compounds with putative health benefits. This objective is of fundamental importance to the Food Quality and Safety priority, and is an essential underpinning component of all food and health research in Europe. The activities aim at durable integration of efforts and the Joint Programme of Activities (JPA) is divided into four horizontal platforms: (1) Integration Activities (6 WPs); (2) Joint Research Activities (4 WPs); (3) Spreading of Excellence Activities (4 WPs), and (4) Network Management (1 WP). The JPA activities promote continuous cross-communication and stimulation and are grouped under 15 individual WPs but have numerous interactions. EuroFIR will be underpinned by a robust and wellestablished web-based software platform tool both to support interactive working between the teams involved and in the spreading of excellence internally and externally (see www.eurofir.net). A series of targeted formats (e.g. web-based interface, scientific publications, popular press and media) and communication channels will be used to deliver and disseminate findings, and transfer of knowledge to a variety of targeted audiences beyond the network. Training of researchers (assuring equal opportunities) and other key staff is indispensable to the development and sustainability of European excellence and will include: specialist workshops, exchange training visits, and a range of courses (including e-learning). This presentation will introduce the EuroFIR project and overview its current activities. This work was completed on behalf of the EuroFIR consortium and funded under the EU 6th Framework Food Quality and Safety Programme. 